\title{
Effects of stress-dependent permeability on well performance of ultra-low permeability oil reservoir in China
}

\author{
Zhang Zhang ${ }^{1} \cdot$ Shunli $\mathrm{He}^{1} \cdot$ Daihong Gu${ }^{1} \cdot$ Shaohua Gai ${ }^{1} \cdot{\text { Guangming } \mathrm{Li}^{2}}^{2}$
}

Received: 15 April 2014/ Accepted: 26 February 2017/Published online: 30 March 2017

(c) The Author(s) 2017. This article is an open access publication

\begin{abstract}
An experimental investigation of the behaviors of stress-dependent permeability under in situ conditions was conducted and discussed, applying cores from an ultra-low permeability oil reservoir in China. The variation characteristics of formation permeability resulting from pore pressure drawdown and increase were compared. The results indicate that formation permeability at any possible location of the reservoir could be altered in response to the change in stress state caused by both oil production and water injection. A mathematical model of fluid flow in stress-sensitive reservoir was established to evaluate the effect of stress changes on well performances, and an analytical solution method was presented. Several analytical simulations under the conditions of constant wellbore flowing pressure were performed to quantitatively assess the impact of stress sensitivity on single well performance. It is demonstrated that despite the stress-dependent permeability can have an adverse impact on production rate and recovery volume, it may be favorable for water injection. Based on the analysis, a practical and efficient waterflooding program was presented to reduce the influence of permeability damage on reservoir productivity. This program was verified by numerical reservoir simulation to have a combined positive effect for development of ultra-low permeability oil reservoir.
\end{abstract}

Keywords Stress-dependent permeability · Ultra-low permeability reservoir $\cdot$ Well performance $\cdot$ Constant flowing pressure $\cdot$ Waterflooding

Zhang Zhang

zhangzhangky@163.com

1 MOE Key Laboratory of Petroleum Engineering, China University of Petroleum, Beijing 102249, China

2 Natural Gas Business Division, PetroChina Tarim Oilfield Company, Xinjiang, China

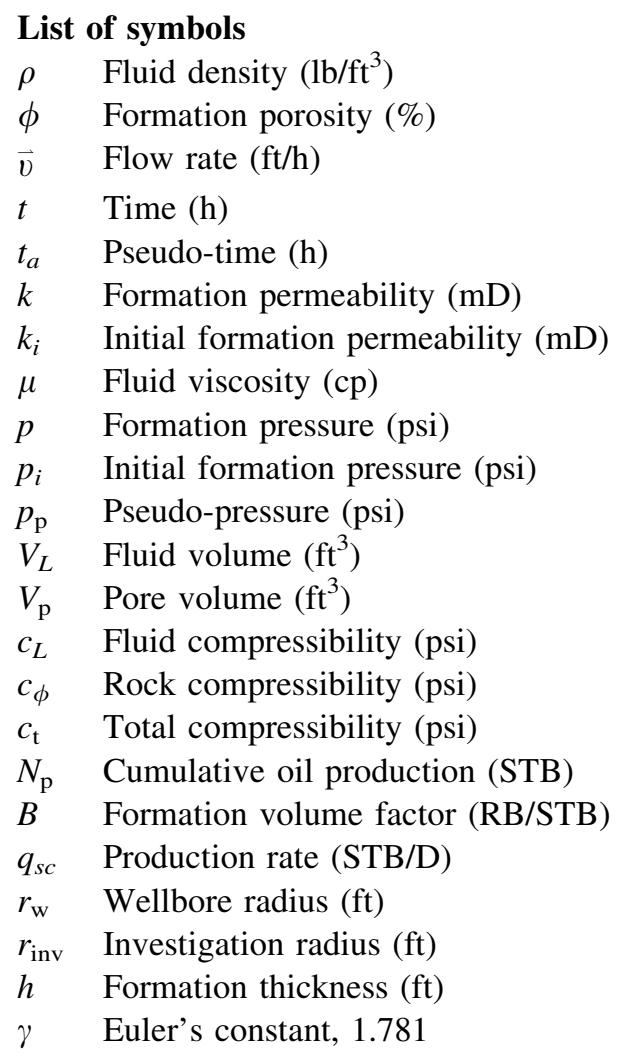

\section{Introduction}

Oil and gas resource embedded in ultra-low permeability reservoirs is an important and aggressively increasing source of hydrocarbon energy in China. One of the problems that we have to consider in developing such reservoirs is the stress-dependent formation properties (permeability and porosity) during the production life cycle of the 
reservoir. In general, producing from a hydrocarbon reservoir may result in a decrease of fluid pressure and thus a subsequent increase of effective overburden load on porous reservoir rock, which will compact the reservoir rock and alter the detailed pore geometry (as a matter of course, injection into a reservoir will have the opposite situation). If fluid flow properties of the reservoir rocks are highly sensitive to effective stress changes and rock deformation, the reservoir should be considered to be stress-sensitive (Chin et al. 2000a).

The characteristics of permeability decrease with increased confining stress have been well demonstrated for a great variety of reservoir rocks in the literature. According to a comprehensive study presented by Davies and Davies (2001), the rock permeability behaves in an exponential manner with the net confining stress variation in most cases, and the greatest variation of permeability occurs dominantly at low pressure (0-3000 psi). In this low-pressure range, rocks can lose between 10 and $99 \%$ of their original permeability. Pore geometry is the fundamental control on stress-dependent permeability in sandstone reservoirs. It has been proved that formations with pore distribution of smaller radio are very sensitive to compressive stress. Besides, the impact of stress on property alteration generally increases with the tightness of the reservoir rock.

As for conventional reservoirs, we have had a clear knowledge of the behavior of flow-reducing properties of formation rocks and the inherent controlling mechanism. Through analytical, numerical, or coupled flow models, the combined effects of stress, fluid flow, and reservoir property changes on well performance have been also widely illustrated in the past decades (Vairogs et al. 1971; Raghavan et al. 1972; Vairogs and Rhoades 1973; Samaniego et al. 1977; Evers and Soeiinah 1977; Ostensen 1986; Chin et al. 2000a, b; Samaniego and Villalobos 2003; Lei et al. 2007). There is a broad consensus that the stressdependent permeability of matrix or natural fractures may have a significant impact on the performance of both the individual well and the reservoir. In order to evaluate reservoirs with stress-dependent permeability accurately, many techniques for quantifying key reservoir properties controlling storage and flow, calculating hydrocarbons in place, establishing recovery and forecasting production have been developed as well (Samaniego et al. 1979; Samaniego and Cinco 1980, 1989; Han and Dusseault 2003; Raghavan and Chin 2004; Chen et al. 2008; Xiao et al. 2009). In addition, with the extensive development of unconventional reservoirs (ex. coalbed methane, shale gas/ oil, ultra-low permeability oil reservoir) around the world, the subject of stress-dependent permeability is also of great interest because the ultra-tight matrix and natural/generated fractures are more susceptible to stress-state changes. Some researchers (Thompson et al. 2010; Okouma et al. 2011; Cho et al. 2013; Clarkson et al. 2013; Qanbari and Clarkson 2013a, b) have chosen to include stress-sensitive effects for more accurate assessments of the production potential of such reservoirs.

Virtually, all the investigations on the stress-sensitive phenomenon mentioned above are mainly concentrated on the permeability decline rule and the influence on fluid flow into a production well. To our knowledge, little research has paid attention to the behavior of formation permeability variation when the reservoir rock is subject to increasing pore pressure due to fluid injection. Because of the extremely small pore throat, the correspondingly ultra-low permeability and lack of natural energy, artificial waterflooding is the preferred development technique for ultralow permeability oil reservoir in China. Thus, compared to other stress-sensitive reservoirs, ultra-low permeability oil reservoir has its unique characteristics: the pore pressure will experience both decrease and increase during development. It is expected that the permeability will change in a more complex manner from the perspective of the whole reservoir.

It is the objective of this work to use experimental data and mathematical models to evaluate the interaction between the stress state and fluid flow and its influence on well performance of an ultra-low permeability reservoir. In this paper, we first demonstrate the results of an experimental study on permeability changes using natural cores prepared from Changqing oilfield in China. Then, we present the basic governing equations under unsteady-state condition for fluid flow in stress-sensitive reservoir and develop an analytical method to solve the nonlinear problem. Based on the analytical solution derived we present several theoretical studies to reveal the complex characteristics of permeability changes and the corresponding production performances of the reservoir. Finally, on the basis of the above research, an optimum water injection schedule was recommended to reduce the enormous consequence of rock deformation on the development of ultralow permeability oil reservoir.

\section{Experimental study}

Although a large number of experimental studies on stressdependent permeability have been discussed in the literature, most of them considered the rock compression process. Experimental data for permeability-stress relationship during the expansion process have not been sufficiently documented. We used eight core samples acquired from the Chang 6 formation in the Baibao district of Changqing oilfield, taken approximately at $6965 \mathrm{ft}$, to obtain experimental data for stress-dependent permeability 
in ultra-low permeability oil reservoir. The Chang 6 formation is mainly comprised with very fine-grained and fine-grained sandstone. The main mineral composition of the rock debris is quartz and feldspar. The petrophysical characterizations of these core samples are shown in Table 1. By means of CT scan profiles of the macro-plug, thin section, and $\mathrm{Hg}$ injection technique we also get knowledge of the fact that abundant invisible microfractures are embodied in core samples from the formation, and though the pore radius of the formation rock is relatively large $(25-30 \mu \mathrm{m})$, its connectivity is constrained by small throat radius $(3-5 \mu \mathrm{m})$. The microfractures and throat radius would enlarge during injection and close during pressure drawdown which may influence the permeability and reservoir development.

The objective of experimental study is to discover the change rules of permeability variation caused by production and injection, and to generate simple but rigorous data for reservoir simulation. The detailed mechanisms that control changes in formation permeability for different rock types are not discussed.

\section{Experimental procedure}

All the cores were cut cylindrically into 1 in diameter sections, and the length of the cores varied from 2.0 to 2.6 in. After the cores were cleaned with tobuence for several days, the displacement experiment was carried out using an AFS-300 displacement system developed by Core Laboratories. Three high-pressure Isco pumps were used to generate flows of fluid through the cores, and control confining and back pressure, respectively. According to the results of well-log and well-testing analysis, the overburden pressure $\left(P_{\mathrm{o}}\right)$ of Chang 6 formation is about $6090 \mathrm{psi}$ and the initial pore pressure $\left(P_{i}\right)$ is about 2420 psi. To simulate the in situ formation stress state, the confining pressure was set at $6090 \mathrm{psi}$ and the back pressure was increased from 2420 to 4620 psi or decreased from 2420 to $250 \mathrm{psi}$. The fluid used in these experiments was standard brine with a viscosity of $1.003 \mathrm{mPa}$. Two sets of experiments, step-down pore pressure and step-up pore pressure, were performed. Flow rate was maintained at $0.01 \mathrm{~mL} / \mathrm{min}$ to avoid any damage due to the high flow rate. The experiment procedures are described as follows.

First, a vacuum pump was used to pump air and other impurities out of the cores. After the core was saturated with brine and weighted, it was set in core holder and then the confining pressure was set to the overburden pressure. When this process was performed, the confining pressure was maintained constant, while the back pressure was adjusted to a given value (initial pore pressure). The displacement pump was started to inject brine to the core and when the flow was stable, the flow rate and the inlet and outlet pressure were recorded, and core permeability was calculated at this pressure level. Then, the back pressure was gradually increased or decreased and the displacement procedure was repeated. The values of permeability and pore pressure of every state were calculated.

\section{Experimental results}

The values of absolute permeability used in core analysis in this study vary between samples. To compare all data, it is necessary to normalize values of permeability at each measure point. We use permeability at initial formation pressure $\left(p_{i}\right)$ as the reference value to study the effect of stress state on formation permeability for each core.

Figure 1 presents the results of the step-up pressure experiment with a starting pore pressure of 2420 psi. Under a constant confining stress condition, the changes in permeability for each of the eight cores during the pressure increase process are similar. In general, as the pore pressure increased from 2420 to $3200 \mathrm{psi}$, the permeability of each core has a significant increase initially and then has a slight increase at pressures of more than approximately 3200 psi. The increments of permeability range from 0 to $9.2 \%$ at different pressure for these tests. Additionally, the magnitude of permeability variation has a certain correlation to initial permeability. Core 7\# and core $8 \#$ have relative high sensitivity to pore pressure change, with the increments of permeability ranging from 0 to $8.2 \%$ and from 0 to $9.2 \%$, respectively, and core $4 \#$ and core $5 \#$ have relative low sensitivity to pore pressure change, with the increments of permeability ranging from 0 to $6.1 \%$ and

Table 1 Petrophysical characterizations of cores

\begin{tabular}{lllllllll}
\hline & 1 & 2 & 3 & 4 & 5 & 6 & 7 \\
\hline Depth (ft) & 6759 & 6972 & 7044 & 6762 & 7051 & 7054 & 7064 & 7060 \\
Diameter (in) & 0.977 & 0.974 & 0.983 & 0.978 & 0.983 & 0.979 & 0.980 & 0.975 \\
Length (in) & 2.522 & 2.430 & 2.068 & 2.634 & 2.210 & 2.474 & 2.474 & 2.350 \\
Porosity (\%) & 13.26 & 11.99 & 17.52 & 13.72 & 16.51 & 17.43 & 11.56 & 13.36 \\
Initial permeability (mD) & 0.362 & 0.141 & 0.113 & 0.052 & 0.055 & 0.115 & 0.315 & 0.266 \\
\hline
\end{tabular}


Fig. 1 Permeability increment versus pore pressure or effective stress

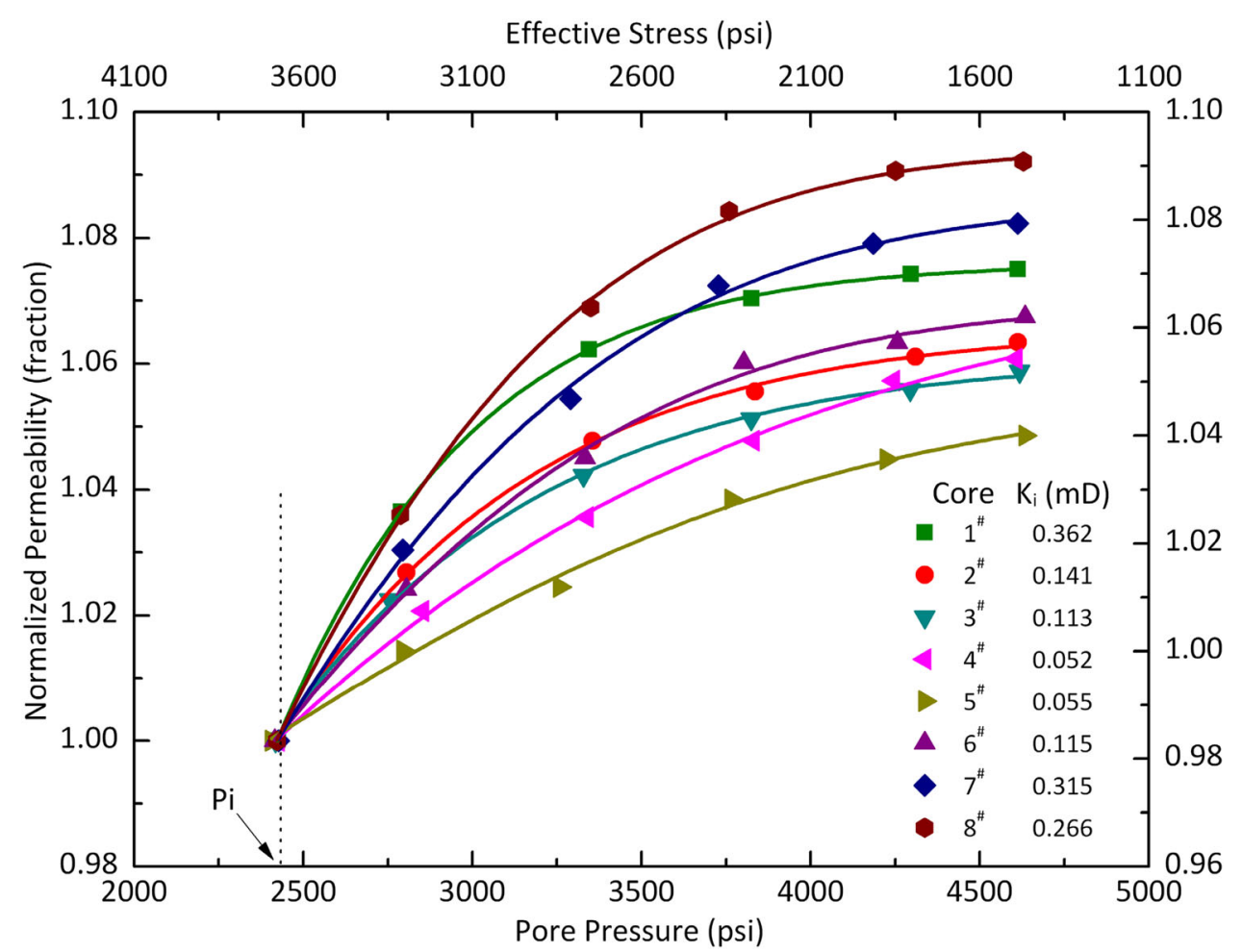

from 0 to $4.8 \%$, respectively. The primary cause for this phenomenon is the intrinsic nature of pore geometry of ultra-low permeability rocks. In ultra-low permeability reservoir, pore throat and microcrack are the main flow path. The permeability for rocks with large throats and well-developed open microcracks will be high. During the initial period of increasing pore pressure, the small throats and microfractures, which control the seepage capability of ultra-low permeability rocks, are enlarged first and this makes a great contribution to core permeability. As the pressure continues to increase, the opening of throats and microcracks is restricted to a certain degree. As a result, the increase rate of permeability is slowed down. At this point, pores in rock play a main role in permeability increase, which is slower due to the difficulty of pore deformation.

Figure 2 presents the results of the step-down pressure experiment with a starting pore pressure of 2420 psi. Under a constant confining stress condition, the changes in permeability for each of the eight cores during the pressure depletion process are also similar. As the pore pressure decreased from 2420 to $250 \mathrm{psi}$, the permeability of each core has a significant decrease initially and then has a slight decrease at pressures of less than approximately 1400 psi. The decrements of permeability range from 0 to $18.3 \%$ at different pressure for these tests. In contrast to the step-up pressure experiments, core $4 \#$ and core $5 \#$ have relative high sensitivity to pore pressure change, with decrements of permeability ranging from 0 to $17.9 \%$ and from 0 to $18.3 \%$, respectively, and core $7 \#$ and core $8 \#$ have relative low sensitivity to pore pressure change, with decrements of permeability ranging from 0 to $11.0 \%$ and from 0 to $12.1 \%$, respectively. The behaviors of permeability variations during pressure decline are also related to the pore geometry of ultra-low permeability rocks.

\section{Mathematical model and solution}

To quantify the effect of stress sensitivity of permeability on well responses, we developed a transient flow model. The basic assumptions usually made about the formation and fluid properties in well test theory are applied. With respect to the stress-sensitive behavior, we assume that the overburden pressure is constant during the life cycle of production, and thus the variation in permeability due to stress change can be described as a single value function of pore pressure.

\section{Governing equations}

The equations governing isothermal single-phase fluid flow in a deformable porous medium with stress-dependent permeability are derived based on mass conservation principles and Darcy's law, as follows:

Mass conservation equation is:

$\frac{\partial(\rho \phi)}{\partial t}+\operatorname{div}(\rho \vec{v})=0$ 
Fig. 2 Permeability reduction versus pore pressure or effective stress

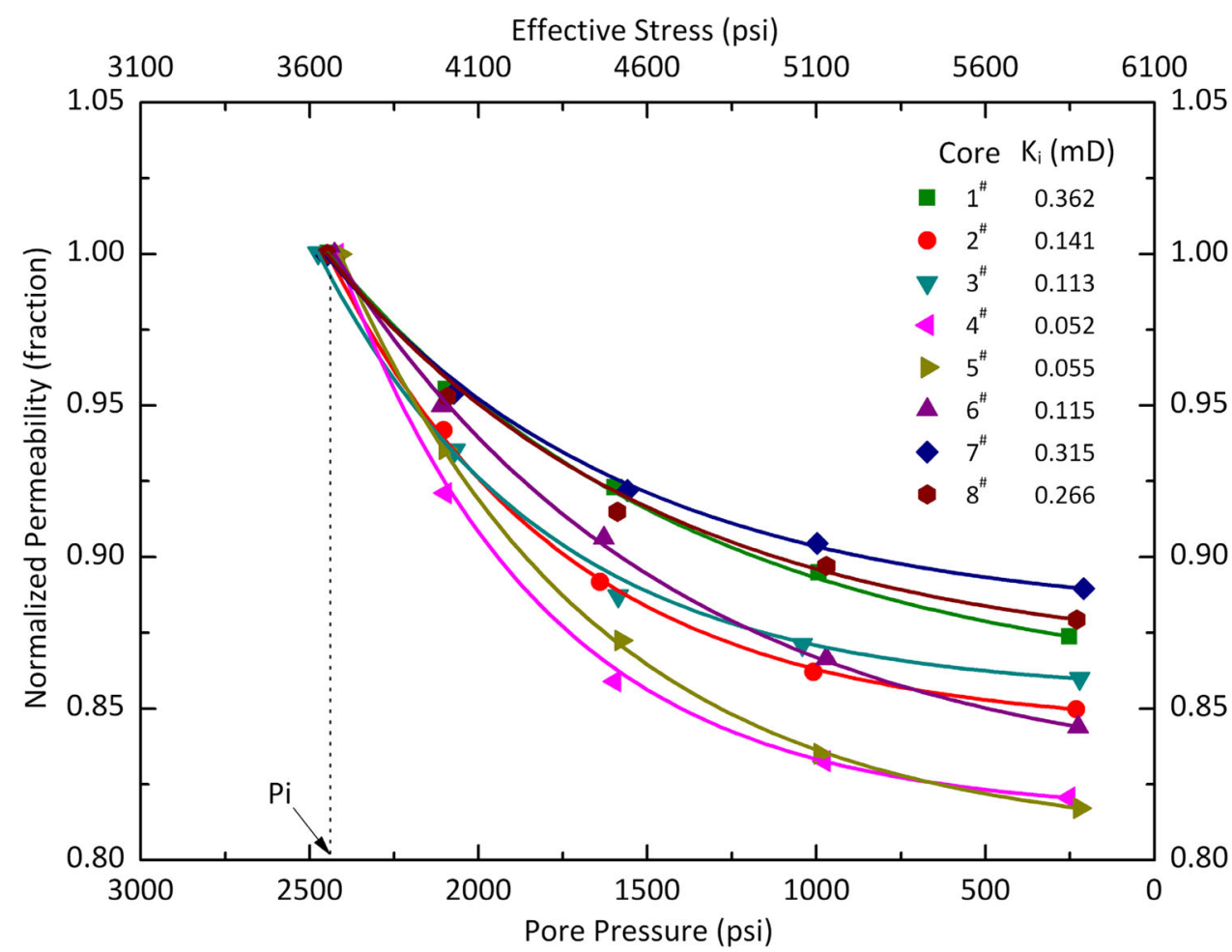

Motion equation is:

$\vec{v}=-0.0002637 \frac{k(p)}{\mu} \nabla p$

Fluid state equation:

Under isothermal condition, the fluid compressibility is defined as

$c_{L}=-\frac{1}{V_{L}} \frac{\mathrm{d} V_{L}}{\mathrm{~d} p}=\frac{1}{\rho} \frac{\mathrm{d} \rho}{\mathrm{d} p}$

By integrating the formula of the fluid compressibility, the fluid state equation is

$\rho=\rho_{0} \mathrm{e}^{-c_{L}\left(p_{i}-p\right)}$

Formation rock state equation:

Under isothermal condition, the formation rock compressibility is defined as

$c_{p}=\frac{1}{V_{\mathrm{p}}} \frac{\mathrm{d} V_{\mathrm{p}}}{\mathrm{d} p}$

An equivalent formula is

$c_{\phi}=\frac{1}{V_{\phi}} \frac{\mathrm{d} V_{\phi}}{\mathrm{d} p}$

By integrating the formula of the rock compressibility, the state equation is

$\phi=\phi_{0} \mathrm{e}^{-c_{\phi}\left(p_{i}-p\right)}$

Substituting the motion equation and state equations into the mass conservation equation and after some algebraic manipulation, the fluid flow control equation can be obtained as follows:

$c_{L}(\nabla p)^{2}+\frac{\mu}{k(p)} \nabla \cdot\left[\frac{k(p)}{\mu} \nabla p\right]=\frac{\phi \mu c_{\mathrm{t}}}{0.0002637 k(p)} \frac{\partial p}{\partial t}$

where

$c_{\mathrm{t}}=c_{L}+c_{\phi}$

is the total compressibility.

If we assume a small and constant compressibility and a constant viscosity, which is required by the equation of state for a slightly compressible liquid, then the quadratic term can be neglected and the fluid flow control equation can be simplified as

$\nabla \cdot[f(p) \nabla p]=\frac{\phi \mu c_{\mathrm{t}}}{0.0002637 k_{i}} \frac{\partial p}{\partial t}$

where $f(p)$ is defined as

$f(p)=k(p) / k_{i}$

Equation 10 is a partial differential equation for singlephase flow of slightly compressible fluid in a reservoir with stress-dependent permeability.

\section{Analytical solution}

Analytical solutions provide an advantageous method for analyzing and modeling well test or production data, which are primarily developed for linear problems of a constant viscosity and compressibility fluid flowing in formations 
with constant porosity and permeability. However, the diffusivity equation (Eq. 10) is strongly nonlinear due to the incorporation of stress-dependent permeability. In this study, we defined two pseudo-parameters considering stress-dependent permeability to linearize the diffusivity equations and then presented an analytical solution method as follows:

Stress-sensitive pseudo-pressure is defined as:

$p_{\mathrm{p}}(p)=\frac{1}{k_{i}} \int_{0}^{p} k(p) \mathrm{d} p=\int_{0}^{p} f(p) \mathrm{d} p$

Stress-sensitive pseudo-time is defined as:

$t_{a}(t)=\frac{1}{k_{i}} \int_{0}^{t} k(\bar{p}) \mathrm{d} t=\int_{0}^{t} f(\bar{p}) \mathrm{d} t$

To solve Eq. 10 properly, the choice of correct average pressure in pseudo-time function is a very important issue. Inspired by Anderson' work (2007), we use average pressure in the region of influence to calculate pseudotime. This average pressure can be calculated using oil material balance equation (Eq. 14).

$N_{\mathrm{p}}=\int_{0}^{t} q_{s c}(t) \mathrm{d} t=\frac{\pi r_{\mathrm{inv}}^{2} \phi h c_{\mathrm{t}}}{0.234 B_{\mathrm{o}}}\left(p_{i}-\bar{p}\right)$

where

$r_{\text {inv }}=\gamma \sqrt{\frac{0.0002637 k_{i} t}{\phi \mu c_{\mathrm{t}}}}$

In this equation, $r_{\text {inv }}$ is the radius of investigation, and $\gamma=1.781$ is Euler's constant.

Through introducing the two pseudo-functions, Eq. 10 can be transformed to new forms which are similar to the conventional diffusivity equation:

$\nabla \cdot \nabla p_{p}=\frac{\phi \mu c_{\mathrm{t}}}{0.0002637 k_{i}} \frac{\partial p_{\mathrm{p}}}{\partial t_{a}}$

Using Boltzmann transformation, Eq. 16 can be solved under constant rate or constant flowing pressure inner boundary condition for a well centered in an infinite circular reservoir.

For constant pressure case, the solution for the wellbore production rate $q_{\mathrm{sc}}\left(t_{\mathrm{a}}\right)$ gives the following equation:

$q_{s c}\left(t_{a}\right)=\frac{k_{i} h}{70.6 \mu B}\left(p_{p i}-p_{p w}\right) \frac{\mathrm{e}^{-\frac{948 \phi \mu_{c} r_{w}^{2}}{k_{i} t_{a}}}}{-E i\left(-\frac{948 \phi \mu c_{c_{\mathrm{w}}} r_{\mathrm{w}}^{2}}{k_{i} t_{a}}\right)}$

Generally, we should plot $q_{\mathrm{sc}}$ as a function $t$ rather than $t_{\mathrm{a}}$. An iterative approach for obtaining $q_{\mathrm{sc}}(t)$ using the equations derived above is presented in Fig. 3.

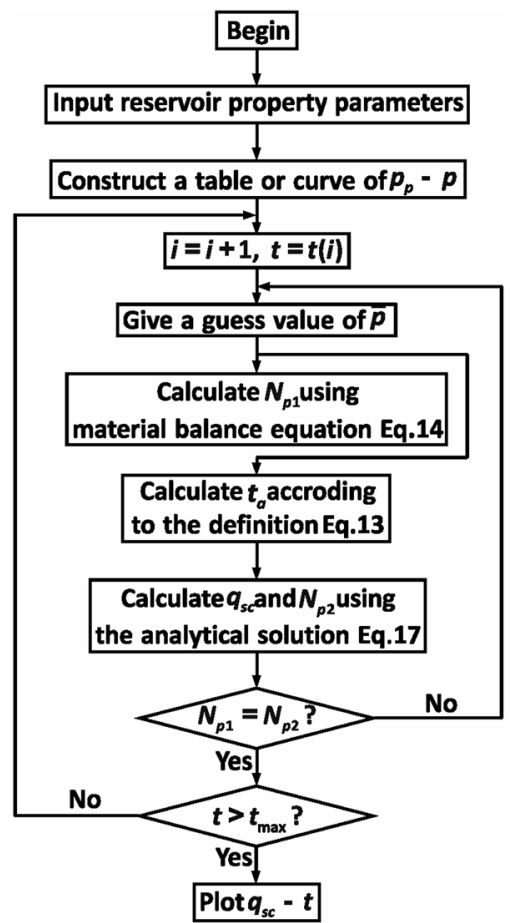

Fig. 3 Analytical solution procedure under constant bottomhole pressure

\section{Results and discussion}

In the following, we will briefly illustrate the fluid flow behavior of a reservoir with stress-dependent permeability and set the stage for our discussion. Because production rate is of vital concern from a reservoir engineering view point, we first examine the change in well productivity in detail. Then, we discuss the response of injecting water into a stress-sensitive reservoir. Finally, an effective development method that would permit us to reduce or eliminate the influence of stress sensitivity for ultra-low permeability reservoir is evaluated.

\section{Fluid flow behavior of single well}

This subsection presents the results of a conceptual model for a single well penetrating an ultra-low permeability oil reservoir using the stress-dependent permeability data and the analytical solution presented in this paper. This model simulates an infinite radial formation with net height of $50 \mathrm{ft}$ and initial pressure of $2420 \mathrm{psi}$. The reservoir and fluid properties are shown in Table 2. Values of stressdependent permeability were calculated based on the development of the relationship between pore pressure and normalized permeability. We chose the experimental data of Core $4 \#$ to conduct the simulations because of its high sensitivity of permeability to pressure depletion. The quantitative relationship between permeability change 
Table 2 Reservoir and fluid properties used for simulation

\begin{tabular}{llllllll}
\hline$r_{\mathrm{w}}(\mathrm{ft})$ & $h(\mathrm{ft})$ & $\Phi(\%)$ & $k_{i}(\mathrm{mD})$ & $P_{i}(\mathrm{psi})$ & $\mu(\mathrm{cp})$ & $B(\mathrm{RB} / \mathrm{STB})$ & $c_{\mathrm{t}}\left(\mathrm{psi}{ }^{-1}\right)$ \\
\hline 0.33 & 50 & 13.72 & 0.052 & 2420 & 1.0 & 1.34 & $1.17 \times 10^{-5}$ \\
\hline
\end{tabular}

induced by rock compaction or expansion and the formation pressure was developed through the curve fitting procedure. Several analytical simulations using the proposed procedure were performed to assess the effect of stress-dependent permeability on well performance of both production and injection well. For each stress-sensitive simulation investigated in this study, a corresponding simulation with non-stress-sensitive permeability (or constant permeability) was also conducted as a reference case to establish a quantitative comparison. In addition, wells in all cases were operated under controlled conditions to make sure that the change in the performance is only a result of permeability variation.

First of all, we focus on the performance of a vertical production well. A series of fluid flow simulations under constant bottomhole pressure conditions were completed examining stress-sensitive effects on well responses in terms of oil production rate and cumulative production. The performances for four cases $\left(P_{w f}=500,1000,1500\right.$, 2000 psi) are compared in this study, as shown in Figs. 4 and 5. Note that incorporation of stress-dependent permeability reduces the production rates to varying degrees, depending on the level of wellbore flowing pressure. For non-stress-sensitive reservoir, additional wellbore pressure drawdown will increase oil production by a similar value compared to the previous pressure drawdown. That is, an linear increase in production rate is created as a result of the reduced wellbore flowing pressure. Whereas, for stresssensitive reservoir, additional pressure drawdown will result in a relatively lower increase in oil production. Although the values of production rates are impacted by the stress-sensitive permeability, the general character of each production rate curve is not changed between the constant permeability case and stress-dependent permeability case.

Based on the simulation results, the radial profiles of permeability around the wellbore for the four cases are plotted to discern the variation of formation permeability in the process of producing, as shown in Fig. 6. As a representative example, the values on day 300 are presented. It is clear that the decrease of bottomhole pressure significantly reduces the permeability along the radius of the reservoir. The 2000 psi case shows the reduction of permeability is less than $10 \%$, while the 500 psi case gives the largest permeability variation up to $18 \%$. However, the radius which has changed permeability values from the

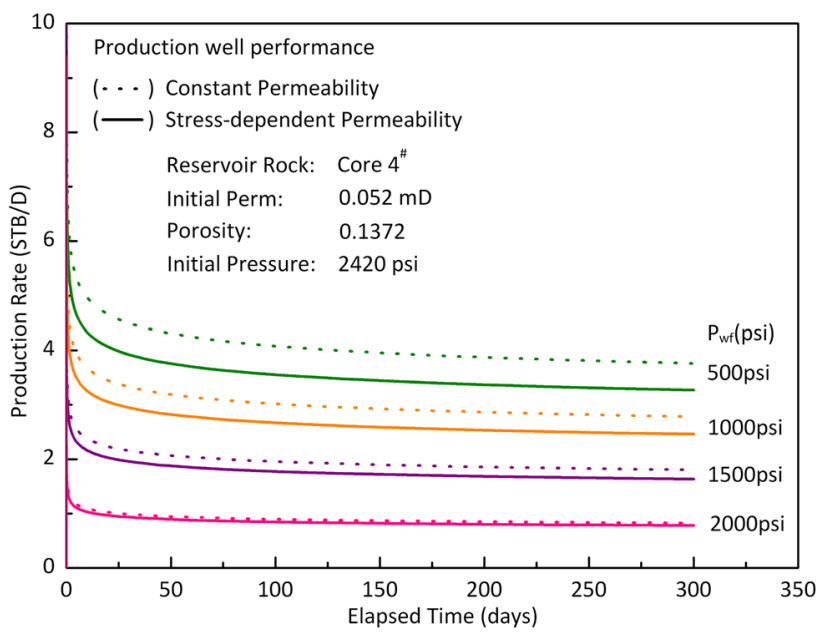

Fig. 4 Production rates under different producing pressures

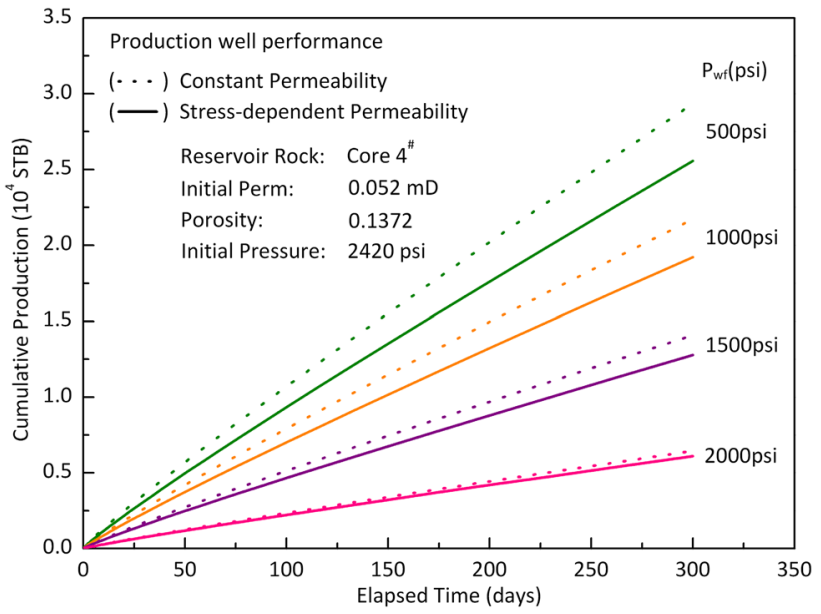

Fig. 5 Cumulative production under different producing pressures

initial permeability is almost the same for the four cases. This figure further confirms that the level of bottomhole pressure can affect the net impact of stress sensitivity.

These simulation results show that reducing the bottomhole pressure to increase the production rate may actually result in a lower increase in production than expected because of the permeability reduction near the wellbore. This also indicates that stress-dependent permeability may be a consideration for attempts to correct the lower-than-expected production rates in many reservoirs. A knowledge of permeability at different values of in situ stress can be used to determine the relationship between 


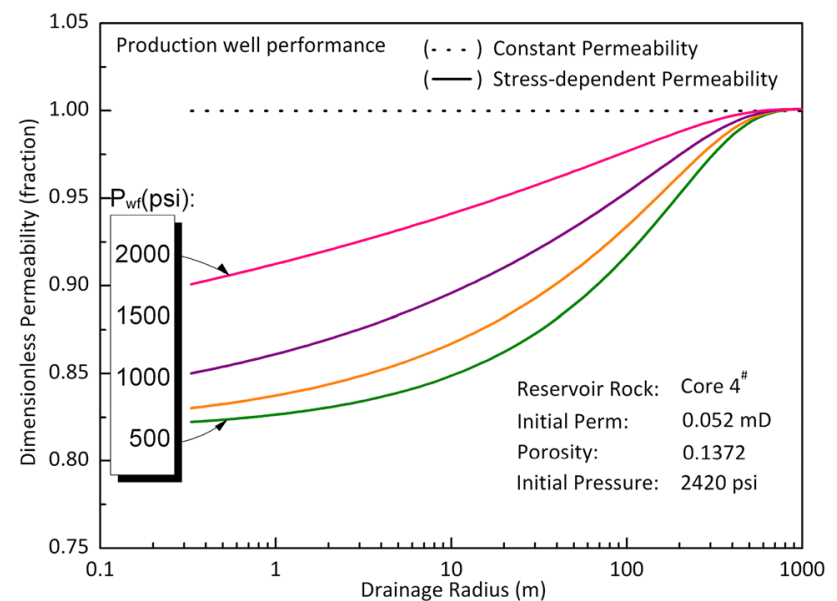

Fig. 6 Permeability distributions on day 300 under different producing pressures

production rate and wellbore pressure and therefore evaluate the formation damage resulting from the rapid drawdown of near-wellbore pressure.

Simulations of water injection well performances of stress-sensitive and non-stress-sensitive reservoir under the condition of constant bottomhole flowing pressure were also conducted. Responses for four cases $\left(P_{w f}=3000\right.$, 3500, 4000, 4500 psi) are compared, as shown in Figs. 7 and 8 . In contrast to the case of production well, the stressdependent permeability enhances the injection rate, but not significantly for all four cases. There are minimal differences in water injection rate between each stress-sensitive case and non-stress-sensitive case, particularly between the cases of low injection pressure. The cumulative injection volume after 300 days is only increased by $1.3 \%$ for the lowest bottomhole flowing pressure case and $3.4 \%$ for the highest bottomhole flowing pressure case.

Figure 9 illustrates the radial profiles of permeability around the wellbore on day 300 for the four stress-sensitive cases. This figure clearly shows that permeability increment around the wellbore occurred. The permeability values around the wellbore area increase with increased bottomhole pressure, but the changes are not as obvious as the producing case. The largest increment in permeability for the 4500 psi case is only $5.8 \%$. This can be attributed to the stress-dependent permeability behavior of Core 4\#. However, the region of influence is large. Even after a relative short injection time of 300 days, increments in permeability can be observed for a distance of about $600 \mathrm{ft}$.

\section{Waterflooding Performance}

The results of the above study indicate that for ultra-low permeability oil reservoirs, injecting water prior to production may reduce the influence of permeability damage

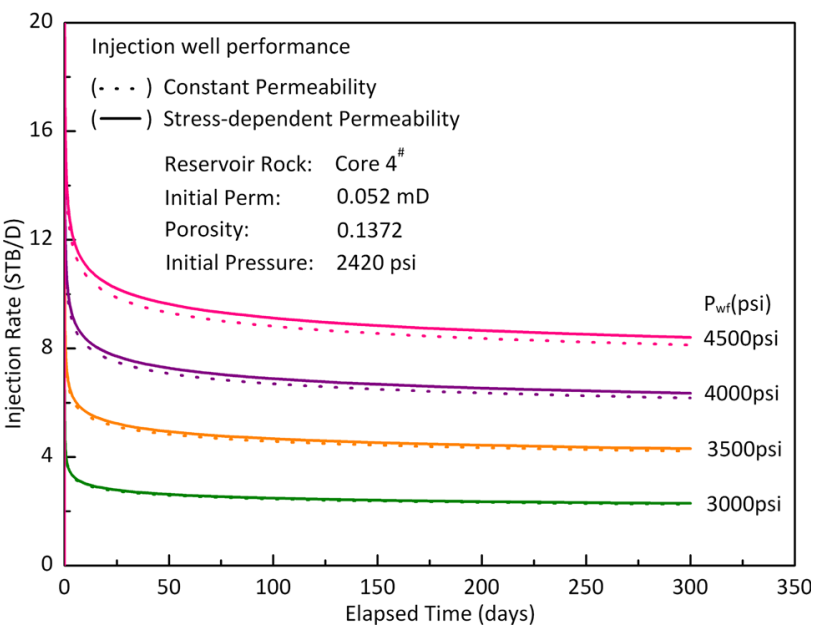

Fig. 7 Injection rates under different injection pressures

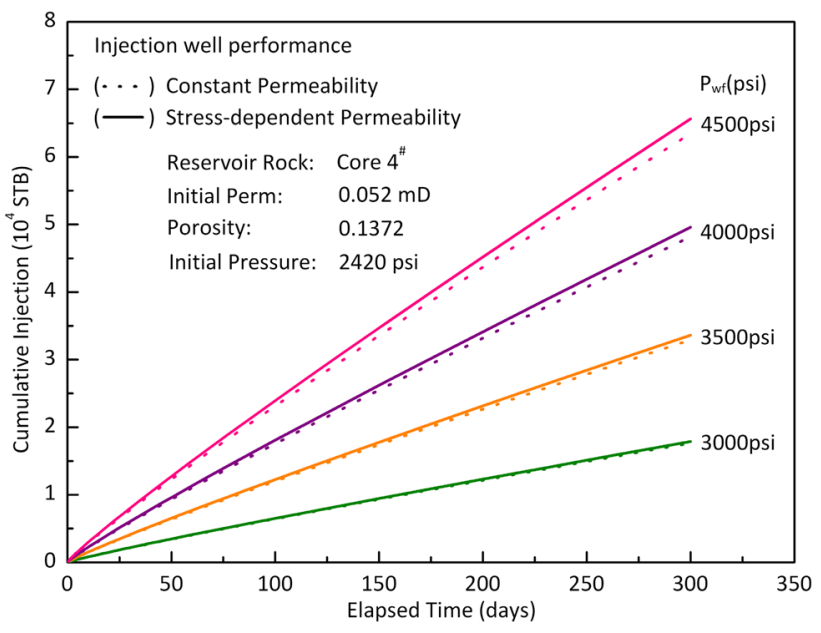

Fig. 8 Cumulative injection under different injection pressures

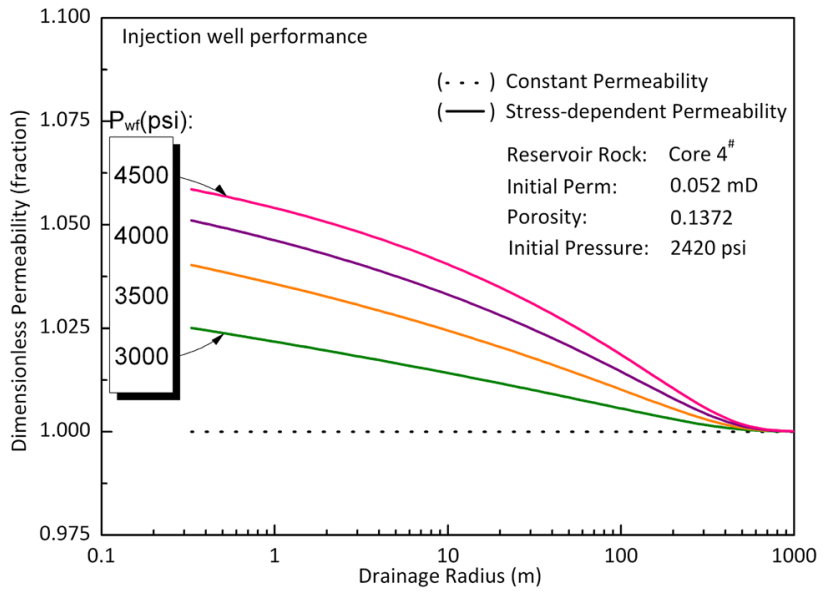

Fig. 9 Permeability distributions on day 300 under different injection pressures 
Fig. 10 Top view of reservoir model

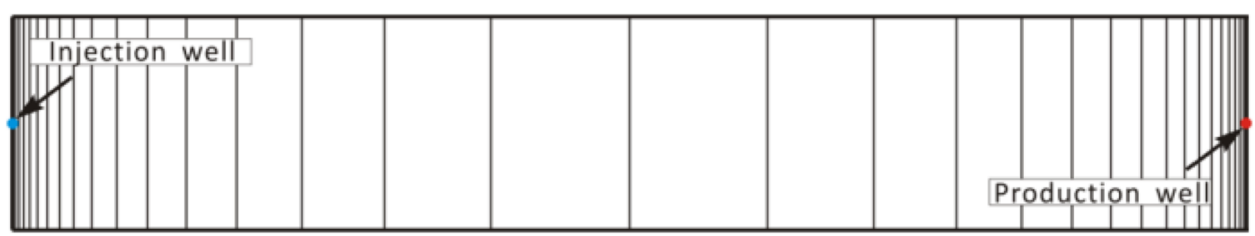

on reservoir productivity. By extending the single-phase model to a two-phase reservoir model, this subsection presents an investigation of the impact of water injection on production performance. The reservoir model is illustrated in detail in Appendix. Figure 10 shows the top view of the numerical model and well locations. Figure 11 is the oil-water relative permeability curves used in the simulation. Two types of water injection patterns were designed and simulated to determine the effect of water injection timing on well productivity of stress-sensitive reservoir: (1) Starting injecting water synchronously with production (synchronous water injection, run 1) and (2) starting injecting water before production (advanced water injection, runs 2-5). For all simulation runs, the bottomhole pressure of production well and injection well is set to 500 and $4000 \mathrm{psi}$, respectively. In this discussion, run 1 is considered as the base case, and the effect of injection timing is quantified by the difference in production rate values between run 1 and the other cases. We set run 1 as the base case lying in the fact that injecting water synchronously with production is a common development method for low-pressure and low permeability oil reservoirs in China, especially for reservoirs that lack an effective waterdrive mechanism.

Oil production rate curves for these five runs are plotted in Fig. 12. This figure clearly shows that an earlier water injection can effectively improve the production rate before day 100 . Among the advanced water injection cases simulated in this study, an initial production increase of 2.4 STB/D can be observed on day 1 over the base case. However, over the course of the following 100 days, the performance for all advanced water injection cases falls in line with that for the base case. Even so, results of cumulative oil production shown in Table 3 demonstrate that injecting water before production significantly enhances the withdraw of the reserves, especially in the early period of production. Table 3 also shows that the earlier water injection begins, the better the development effect will be.

Figures 13 and 14 present the variation of average formation pressure and permeability as a function of time during production, respectively. It is evident that advanced injection imparts significant additional energy for production and thus slows down the reduction rate of permeability, which is a combined active effect for reservoir development.

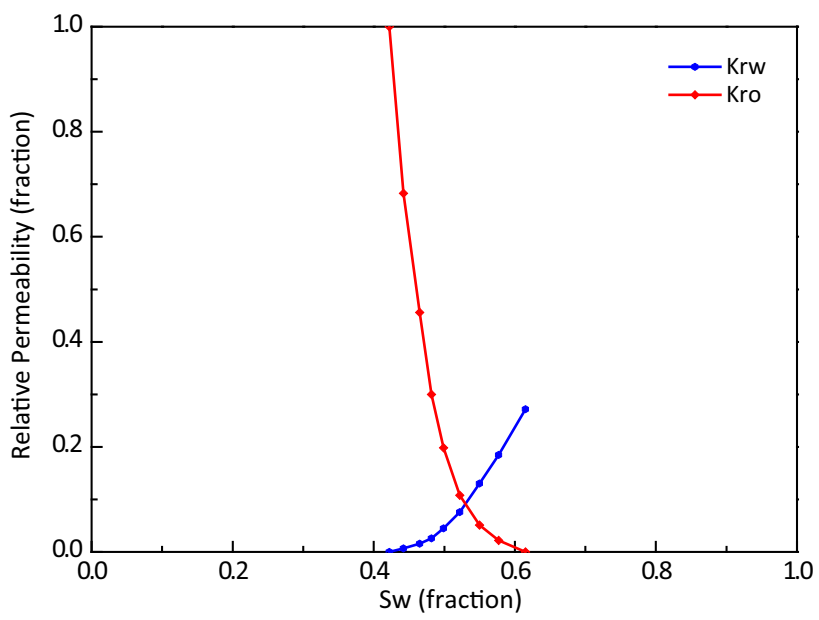

Fig. 11 Relative permeability curves by core experiments

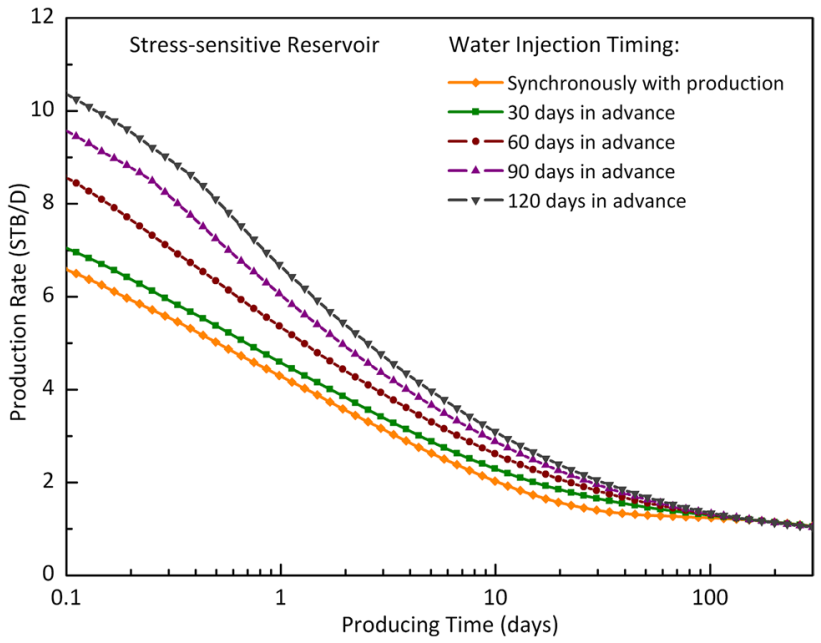

Fig. 12 Oil production rates of waterflooding under different water injection timing

At this stage, we have investigated and understood the behavior of stress-dependent permeability, as well as its influence on the performance of the individual well in an ultra-low permeability reservoir. It is important to point out that, stress sensitivity has not only negative effects but also positive connotations for some reservoirs, depending on rock types and well-producing conditions. Reducing bottomhole pressure to obtain rapid production rates can result in a significant reduction of near-wellbore permeability in stress-sensitive reservoir. However, it has been revealed that advanced water injection will provide remediation due 
Table 3 Cumulative oil production $\mathrm{N}_{\mathrm{p}}$ under different water injection timing

\begin{tabular}{llllllll}
\hline Run & $\begin{array}{l}\text { Advanced time } \\
\text { (days) }\end{array}$ & $\begin{array}{l}N_{\mathrm{p}} \text { after 100 days } \\
(\mathrm{STB})\end{array}$ & $\begin{array}{l}\text { Increment of } N_{\mathrm{p}} \\
(\%)\end{array}$ & $\begin{array}{l}N_{\mathrm{p}} \text { after } 200 \text { days } \\
(\mathrm{STB})\end{array}$ & $\begin{array}{l}\text { Increment of } N_{\mathrm{p}} \\
(\%)\end{array}$ & $\begin{array}{l}N_{\mathrm{p}} \text { after } 300 \text { days } \\
(\mathrm{STB})\end{array}$ & $\begin{array}{l}\text { Increment of } N_{\mathrm{p}} \\
(\%)\end{array}$ \\
\hline 1 & 0 (base case) & 151.1 & 0.00 & 267.7 & 0.00 & 377.2 & 0.00 \\
2 & 30 & 167.8 & 11.01 & 285.4 & 6.60 & 394.1 & 4.50 \\
3 & 60 & 181.8 & 20.29 & 299.6 & 11.89 & 407.6 & 8.06 \\
4 & 90 & 193.0 & 27.75 & 310.9 & 16.12 & 418.3 & 10.91 \\
5 & 120 & 201.6 & 33.43 & 319.5 & 19.33 & 426.4 & 13.06 \\
\hline
\end{tabular}

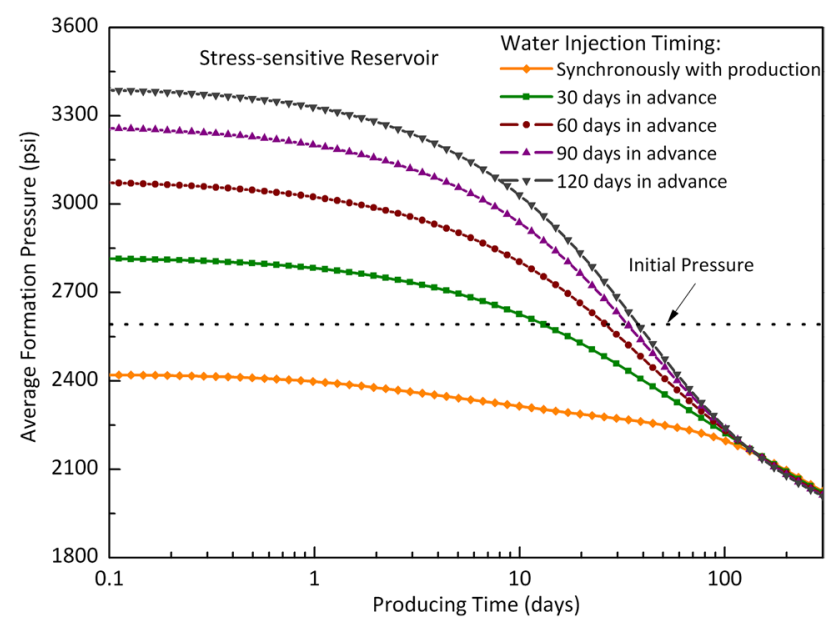

Fig. 13 Average formation pressure under different water injection timing

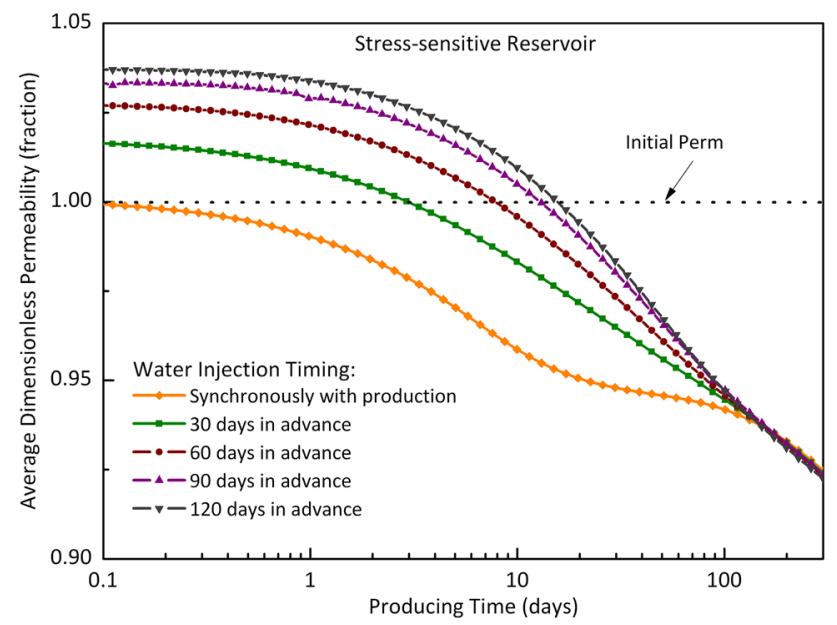

Fig. 14 Average formation permeability under different water injection timing

to its two important positive roles as noted earlier. Since the injection timing and volume are functions of economics and individual reservoir properties, the optimization job should be conducted in terms of the situation of particular reservoir and hence it is not illustrated in this study.

\section{Conclusions}

In this paper, stress-dependent permeability and its effect on the performance of wells in ultra-low permeability reservoir were discussed. The conclusions of this study are as follows: (1) We investigated the change behaviors of permeability under the condition of both pore pressure drawdown and increase through laboratory experiments. Based on the experimental results, it is reasonable to say that the process of oil production and water injection may have profound effects on formation permeability. (2) On the basis of the theory of fluid mechanics in porous media, a flow mathematical model considering stress-dependent permeability was established to reveal the dynamic flowing characteristics of stress-sensitive reservoir during oil production and water injection. (3) With an analytical solution of a conceptual infinite reservoir model, effects of stressdependent permeability on well performance under constant flowing pressure conditions were examined in detail. Results showed that although the impact of stress on permeability is disadvantageous during production, it may be favorable during water injection. (4) Advanced water injection is a practical development method for ultra-low permeability reservoirs. Starting injecting water before production could not only impart significant additional energy for production but also slow down the reduction rate of permeability, which is a combined active effect for reservoir development.

Acknowledgements This work is supported by the National Science and Technology Major Project (Project No. 2011ZX05009-004). The authors would express their appreciation to the Project for contribution of research fund. Thanks are also due to Professor Wei Liu for valuable discussion on this paper.

Open Access This article is distributed under the terms of the Creative Commons Attribution 4.0 International License (http:// creativecommons.org/licenses/by/4.0/), which permits unrestricted use, distribution, and reproduction in any medium, provided you give appropriate credit to the original author(s) and the source, provide a link to the Creative Commons license, and indicate if changes were made. 


\section{Appendix}

The reservoir model is a two-phase and two-dimensional numerical model, which is built with identical parameters to the single-phase model except for the reservoir size, the mobile phase and the well patterns. The reservoir length, width, and thickness are 200,50 , and $50 \mathrm{ft}$, respectively, and irregular spatial gird system is used to generate the simulation model. One production well and one injection well are located at the two sides of the reservoir, both operated at constant bottomhole flowing pressure.

With regard to the liquid model, we assume a water-oil two-phase system with no free gas and no dissolved gas for simplifying the matter. A representative average water-oil relative permeability curve was derived for the simulations of the two-phase flow in the porous medium, through normalizing a large amount of core experimental data of an ultra-low permeability reservoir in Changqing oilfield (Fig. 11). In addition, the saturation and pressure distributions are initialized using equilibrium calculation method.

\section{References}

Anderson DM, Mattar L (2007) An improved pseudo-time for gas reservoirs with significant transient flow. J Can Pet Technol 46(7):49-54

Chen S, Li H, Zhang Q et al (2008) A new technique for production prediction in stress-sensitive reservoirs. J Can Pet Technol 47(3):49-54

Chin LY, Raghavan R, Thomas LK (2000a) Fully coupled geomechanics and fluid-flow analysis of wells with stress-dependent permeability. SPE J 5(1):32-45

Chin LY, Raghavan R, Thomas LK (2000b) Fully coupled analysis of well responses in stress-sensitive reservoirs. SPE Res Eval Eng 3(5):435-443

Cho Y, Apaydin OG, Ozkan E (2013) Pressure-dependent naturalfracture permeability in shale and its effect on shale-gas well production. SPE Res Eval Eng 16(2):216-228

Clarkson CR, Qanbari F, Nobakht M et al (2013) Incorporating geomechanical and dynamic hydraulic-fracture-property changes into rate-transient analysis: example from the Haynesville shale. SPE Res Eval Eng 16(3):303-316

Davies JP, Davies DK (2001) Stress-dependent permeability: characterization and modeling. SPE J 6(2):224-235
Evers JF, Soeiinah E (1977) Transient tests and long-range performance predictions in stress-sensitive gas reservoirs. J Pet Technol 29(8):1025-1030

Han G, Dusseault MB (2003) Description of fluid flow around a wellbore with stress-dependent porosity and permeability. J Pet Sci Eng 40(1):1-16

Lei Q, Yuang J, Cui Y et al (2007) Analysis of stress sensitivity and its influence on oil production from tight reservoirs. In: SPE eastern regional meeting. doi:10.2118/111148-MS

Okouma V, Guillot F, Sarfare M et al (2011) Estimated ultimate recovery (EUR) as a function of production practices in the Haynesville shale. In: SPE annual technical conference and exhibition. doi:10.2118/147623-MS

Ostensen RW (1986) The effect of stress-dependent permeability on gas production and well testing. SPE Form Eval 1(3):227-235

Qanbari F, Clarkson CR (2013a) Analysis of transient linear flow in stress-sensitive formations. SPE Res Eval Eng 17(1):98-104

Qanbari F, Clarkson CR (2013b) A new method for production data analysis of tight and shale gas reservoirs during transient linear flow period. J Nat Gas Sci Eng 14:55-65

Raghavan R, Chin LY (2004) Productivity changes in reservoirs with stress-dependent permeability. SPE Res Eval Eng 7(4):308-315

Raghavan R, Scorer JDT, Miller FG (1972) An investigation by numerical methods of the effect of pressure-dependent rock and fluid properties on well flow tests. SPE J 12(3):267-275

Samaniego V, Cinco L (1980) Production rate decline in pressuresensitive reservoirs. J Can Pet Technol 19(3):75-86

Samaniego F, Cinco L (1989) On the determination of the pressuredependent characteristics of a reservoir through transient pressure testing. In: SPE annual technical conference and exhibition. doi:10.2118/19774-MS

Samaniego VF, Villalobos LH (2003) Transient pressure analysis of pressure-dependent naturally fractured reservoirs. J Pet Sci Eng 39(1):45-56

Samaniego V, Brigham WE, Miller FG (1977) An investigation of transient flow of reservoir fluids considering pressure-dependent rock and fluid properties. SPE J 17(2):141-150

Samaniego V, Brigham WE, Miller FG (1979) Performance-prediction procedure for transient flow of fluids through pressuresensitive formations. J Pet Technol 31(6):779-786

Thompson JM, Nobakht M, Anderson DM (2010) Modeling well performance data from overpressured shale gas reservoirs. In: SPE Canadian unconventional resources and international petroleum conference. doi:10.2118/137755-MS

Vairogs J, Rhoades VW (1973) Pressure transient tests in formations having stress-sensitive permeability. J Pet Technol 25:965-970

Vairogs J, Hearn CL, Dareing DW et al (1971) Effect of rock stress on gas production from low-permeability reservoirs. J Pet Technol 23(9):1161-1167

Xiao X, Sun HD, Han Y et al (2009) Dynamics characteristics evaluation methods of stress-sensitive abnormal high pressure gas reservoir. In: SPE annual technical conference and exhibition. doi: $10.2118 / 124415-\mathrm{MS}$ 